\title{
Effects of resveratrol on the proliferation, apoptosis and telomerase ability of human A431 epidermoid carcinoma cells
}

\author{
XIAO-XIANG ZHAI ${ }^{1}$, JI-CUN DING ${ }^{2}$, ZHI-MING TANG ${ }^{1}$, JING-GUO LI ${ }^{1}$, \\ YONG-CONG LI ${ }^{1}$, YUE-HUA YAN ${ }^{3}$, JING-CHANG SUN ${ }^{4}$ and CUI-XIA ZHANG ${ }^{1}$ \\ ${ }^{1}$ Department of Dermatology, Traditional Chinese Medicine Hospital of Xuzhou City, Xuzhou, Jiangsu 221003; \\ ${ }^{2}$ Department of Plastic Surgery, Xuzhou Central Hospital, Xuzhou, Jiangsu 221009; ${ }^{3}$ Department of Dermatology, \\ Zhongnan Hospital of Wuhan University, Wuhan, Hubei 430071; ${ }^{4}$ Cell Biology Laboratory, School \\ of Basic Medicine, Shandong Medical University, Jinan, Shandong 250355, P.R. China
}

Received October 7, 2015; Accepted March 18, 2016

DOI: $10.3892 / 01.2016 .4351$

\begin{abstract}
The aim of the present study was to investigate the effect of resveratrol on cell apoptosis, ability of telomerase and the human telomerase reverse transcriptase (hTERT) protein expression in human A431 epidermoid carcinoma cells. A431 cells were treated with different concentrations of resveratrol, and the cell appearance was then observed under a microscope. In addition, the cell proliferation was examined using an MTT assay, and the ability of telomerase was detected using telomeric repeat amplification protocol-polymerase chain reaction-ELISA. Resveratrol significantly inhibited the ability of telomerase and decreased the expression of hTERT protein in a concentration-dependent manner. In conclusion, resveratrol is capable of downregulating the expression of hTERT protein and inhibits the ability of telomerase of A431, which is an important mechanism of action of resveratrol with regard to inhibition of A431 cell proliferation.
\end{abstract}

\section{Introduction}

Resveratrol is a non-flavonoid polyphenolic compound with a stilbene structure that has various biological activities and pharmacological effects. Previous findings showed that resveratrol induces apoptosis of various tumor cells and inhibits their proliferation, thereby exerting antitumor effects (1). Additionally the antitumor effect of resveratrol is associated with the inhibition of telomerase $(2,3)$. Telomerase is a specific chromosome terminal transferase and telomerase activity has been reported to be detected in many malignant tumor cells but is undetectable in normal cells. The transition process of normal cells to tumor cells is mostly accompanied

Correspondence to: Ji-Cun Ding, Department of Plastic Surgery, Xuzhou Central Hospital, 199 Jiefang South Road, Xuzhou, Jiangsu 221009, P.R. China

E-mail: djicun@126.com

Key words: resveratrol, A431 cell, cell apoptosis, proliferation, telomerase with telomerase activation (4). Telomerase activation is one of the key links in malignant tumors, and the catalytic subunit of human telomerase reverse transcriptase (hTERT) is closely associated with the activation of telomerase, which exhibits a positive correlation $(5,6)$. At present, little is known concerning resveratrol inducing apoptosis of skin cancer cells and its effect on the activity of telomerase. In the present study, resveratrol intervention was used on cultured human A431 epidermoid carcinoma cells, and its value-added influence on A431 cell apoptosis and telomerase activity was observed. The findings provided a theoretical basis for the use of resveratrol in the clinical treatment of skin tumors.

\section{Materials and methods}

Materials. Resveratrol was purchased from Alexis Biochemicals Corp. (San Diego, CA, USA). The A431 cell line was obtained from the China Center for Type Culture Collection of Wuhan University (Wuhan, China). The main reagents used in the study were, DMEM high glucose medium (Gibco, Grand Island, NY, USA), fetal bovine serum (FBS) (Hangzhou Sijiqing Biological Engineering Materials Co., Ltd., Hangzhou, China), trypsin and DMSO (Amresco, LLC, Solon, OH, USA), as well as a telomeric repeat amplification protocol (TRAP)-polymerase chain reaction (PCR)-ELISA telomerase activity assay kit (Roche Diagnostics $\mathrm{GmbH}$, Boehringer Mannheim, Germany). The main instruments employed in the study were automatic enzyme mark instrument, type ELx808 (BioTek Instruments, Inc., Winooski, VT, USA), and for PCR amplification, an Applied Biosystems Veriti 96-Well Thermal Cycler (Thermo Fisher Scientific, Waltham, MA, USA).

Cell culture. A431 cells $\left(1 \times 10^{7} \mathrm{ml}\right)$ were inoculated in DMEM medium containing $10 \% \mathrm{FBS}$, and cultured in an incubator at $37^{\circ} \mathrm{C}, 5 \% \mathrm{CO}_{2}$ and saturated humidity. The medium was changed every 3 days, and the cells were observed under an inverted microscope (Olympus IX83, Olympus Corporation, Tokyo, Japan). At $100 \%$ cell confluence, $0.25 \%$ trypsin was used to digest the culture cell lines. Cells of the logarithmic growth phase were chosen for experiments. 

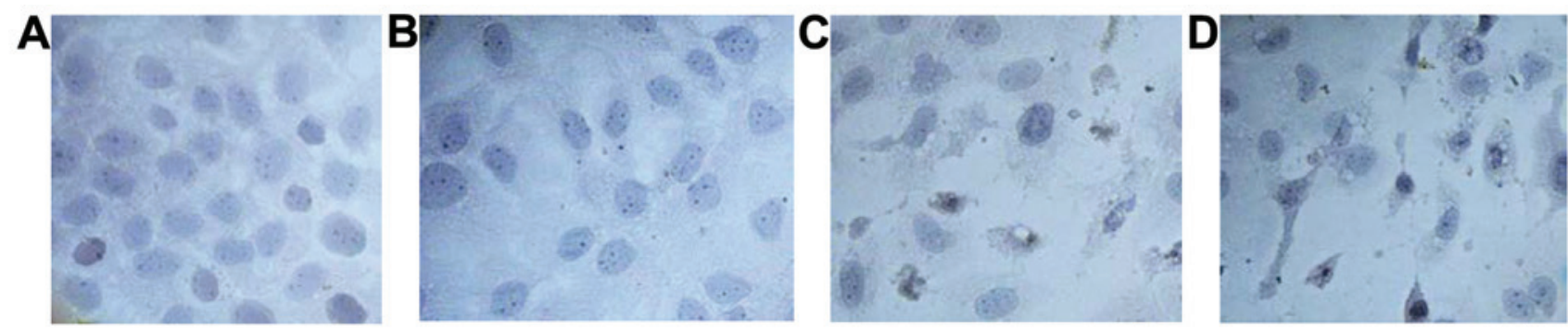

Figure 1. Morphological changes after $24 \mathrm{~h}$ of treatment of different concentrations of resveratrol to A431 cells. (A) Control group, the cells adhered firmly with good growth, normal cell morphology, little cytoplasmic granules and without apoptotic bodies. (B-D) Apoptotic features at different degrees are evident in A431 cells under a contrast microscope. Cells were stained with hematoxylin and eosin (magnification, $\mathrm{x} 400$ ).

Grouping and administration of medications. A431 cells of the fourth generation in the logarithmic growth phase were selected, digested with $0.25 \%$ trypsin, and counted under a light microscope. At $2 \times 10^{4} / \mathrm{ml}$ concentration, the cells were inoculated into 96 -well plates. After $24 \mathrm{~h}$ of pretreatment with serum-free culture medium, the cells were randomly divided into the blank control group (group A), and three drug concentration groups: group B $(0.1 \mathrm{mg} / \mathrm{ml}$ concentration), group C $(0.2 \mathrm{mg} / \mathrm{ml}$ concentration), and group D $(0.3 \mathrm{mg} / \mathrm{ml}$ concentration), each with 8 wells.

Cell morphology. After $24 \mathrm{~h}$ incubation with different doses $(0.1,0.2$ and $0.3 \mathrm{mg} / \mathrm{ml}$ concentration) of resveratrol, the cells were fixed with $4 \%$ paraformaldehyde in 96-well plates at room temperature (RT) for $30 \mathrm{~min}$. Formaldehyde was then washed with distilled water, and hematoxylin and eosin staining was used to observe the morphological changes of A431 cells under an optical microscope.

Status of A431 cell proliferation at different concentrations of resveratrol intervention by MTT assay. Resveratrol was dissolved in DMSO to the desired concentration, and was added to the three drug concentration groups as mentioned above. In addition, $20 \mu \mathrm{l}$ 1\% DMSO/20 $\mu \mathrm{l}$ DMEM was added into each well of the blank control group. After $24 \mathrm{~h}$ of drug intervention, $5 \mathrm{mg} / \mathrm{ml}$ MTT [made by $\mathrm{pH} 7.4$ phosphate-buffered saline (PBS); NDP-1201, Ningbo Novatech Biotechnology Co., Ltd. Ningbo, China] $20 \mu \mathrm{l}$, was added to each well and incubated at $37^{\circ} \mathrm{C}$ for $4 \mathrm{~h}$. The supernatant was carefully absorbed, $150 \mu \mathrm{l}$ DMSO was added per well with oscillation for $10 \mathrm{~min}$, and the crystalline particles were produced and dissolved into homogeneous blue purple, with zero blank well. The absorbance (A) value of each well was determined by the enzyme mark instrument at a wavelength of $490 \mathrm{~nm}$.

Effect of resveratrol on telomerase activity of A431 cells. The resveratrol was dissolved in DMSO to the desired concentration, $20 \mu \mathrm{l}$ was added into the 3 drug concentration groups as described above in each well, and $20 \mu 1$ of $1 \%$ DMSO/DMEM was added into each well of the blank control group. The cells were collected in accordance with the standard method after $24 \mathrm{~h}$ of incubation at $37^{\circ} \mathrm{C}$. Each reaction of $2 \times 10^{5}$ cells was moved into a new Eppendorf tube (Shanghai Hao Ran Biological Technology Co., Ltd. hanghai, China), assayed according to a TRAP-PCR-ELISA telomerase activity assay kit (BMK018-1, Hao Ran Biological Technology Co., Ltd.,
Shanghai, China), and the absorbance (A) value was determined by the enzyme mark instrument at $690 \mathrm{~nm}$ wavelength with the reference wavelength of $450 \mathrm{~nm}$, and calculated as $\mathrm{A}=\mathrm{A}_{450 \mathrm{~nm}}-\mathrm{A}_{690 \mathrm{~nm}}$, where the value of $\mathrm{A}$ indicated the activity of telomerase.

Effect of resveratrol on hTERT protein level in A431 cells. Western blot analysis was used for detection. According to the groupings and doses, after $24 \mathrm{~h}$ culture at $37^{\circ} \mathrm{C}$, the cells were collected, washed twice with pre-cold PBS, cell lysate was added, and was kept on ice for 10-20 min. The cells were removed with a cell scraper and homogenized, at $4^{\circ} \mathrm{C}$, and centrifuged for $10 \mathrm{~min}$, at $300 \mathrm{x} \mathrm{g}$. The supernatant was removed and 1/3 volume of $4 \mathrm{X}$ sample buffer was added, and the solution was boiled for 10 min until protein denaturation. The sample proteins were separated by gel electrophoresis, power was transferred to the nitrocellulose membrane, after $1 \mathrm{~h}$ closed at the RT, and the hTERT monoclonal antibody (1:500) was added and incubated overnight at $4^{\circ} \mathrm{C}$. After rinsing, goat anti-rabbit immunoglobulin $\mathrm{G}$ (1:500) labeled with $37 \%$ horseradish peroxidase was added, and incubated for $1 \mathrm{~h}$. Subsequent to rinsing, staining was shown by enhanced chemiluminescence with exposure, and the film was washed. The ratio of the density gray value of the hTERT protein band and internal control $\beta$-actin protein band was considered as the relative level of protein expression.

Statistical analysis. Experimental data were analyzed using the SPSS 12.0 software (SPSS, Inc., Chicago, IL, USA) package and expressed as mean \pm standard deviation. The mean comparison of multiple groups by single factor variance analysis was tested by t-test.

\section{Results}

Resveratrol induces morphological changes in A431 cell apoptosis. After $24 \mathrm{~h}$ of treatment with resveratrol, apoptotic features at different degrees were observed in A431 cells (groups B, C and D) under a contrast microscope. However, due to the poor adherence of cells to the wall, the cell morphology was not regular, cytoplasm was condensed, particles in the cytoplasm increased significantly with karyopyknosis, and some cells showed nuclear fragmentation, and apoptotic bodies. In addition, an aliquot of the cells were floating in the culture medium. This effect was enhanced with the increased resveratrol concentration, whereas in the control group (A), 
Table I. Effect of different resveratrol concentrations on the proliferation of A431 cells (mean $\pm \mathrm{SD}, \mathrm{n}=6$ ).

\begin{tabular}{lcc}
\hline Groups & Concentration & A value \\
\hline A & - & $0.485 \pm 0.050$ \\
B & $0.1 \mathrm{mg} / \mathrm{ml}$ & $0.228 \pm 0.018^{\mathrm{a}}$ \\
C & $0.2 \mathrm{mg} / \mathrm{ml}$ & $0.177 \pm 0.016^{\mathrm{a}}$ \\
D & $0.3 \mathrm{mg} / \mathrm{ml}$ & $0.155 \pm 0.008^{\mathrm{a}}$ \\
\hline
\end{tabular}

Compared with the blank control group, ${ }^{\text {a }}<0.01$. SD, standard deviation.

Table II. Effect of different resveratrol concentrations on telomerase activity of A431 cells (mean $\pm \mathrm{SD}, \mathrm{n}=6$ ).

\begin{tabular}{lcc}
\hline Groups & Concentration & Telomerase activity \\
\hline A & - & $0.719 \pm 0.064$ \\
B & $0.1 \mathrm{mg} / \mathrm{ml}$ & $0.623 \pm 0.068^{\mathrm{a}}$ \\
C & $0.2 \mathrm{mg} / \mathrm{ml}$ & $0.608 \pm 0.057^{\mathrm{b}}$ \\
D & $0.3 \mathrm{mg} / \mathrm{ml}$ & $0.506 \pm 0.043^{\mathrm{b}}$
\end{tabular}

Ccompared with the blank control group ${ }^{\mathrm{a}} \mathrm{P}<0.05$, ${ }^{\mathrm{b}} \mathrm{P}<0.01$. SD, standard deviation.

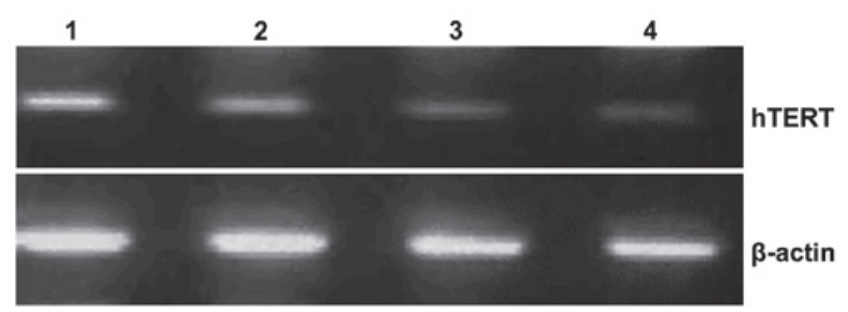

Figure 2. Inhibition of resveratrol on human telomerase reverse transcriptase (hTERT) protein level of A431 cells. 1, blank control group; 2, 3 and 4, drug group $(0.1,0.2$ and $0.3 \mathrm{mg} / \mathrm{ml})$.

the cells adhered firmly with good growth, normal cell morphology, little cytoplasmic granules and without apoptotic bodies (Fig. 1).

Effect of resveratrol on A431 cell proliferation. A431 cells were treated with different concentrations of resveratrol $(0.1$, 0.2 and $0.3 \mathrm{mg} / \mathrm{ml})$. The MTT assay was used to detect cell proliferation. The results showed that compared to the blank control group, the resveratrol group significantly inhibited the proliferation of A431 cells $(\mathrm{P}<0.01)$ in a dose-dependent manner (Table I).

Effect of resveratrol on telomerase activity of A431 cells. After $24 \mathrm{~h}$ of resveratrol treatment, the telomerase activity of A431 cells was significantly inhibited compared to the control group without treatment $(\mathrm{P}<0.01)$ (Table II). An increase in drug concentration led to an increase in the inhibition of the telomerase activity.
Effect of resveratrol on the hTERT protein level in A431 cells. After 24-h treatment of A431 cells with different concentrations of resveratrol, the hTERT protein level was decreased significantly as detected by western blot analysis. Matlab image analysis software [China Daheng (Group) Co., Ltd. Beijing Image Vision Technology Branch, Beijing China] analyzed the relative gray value for the blank control and resveratrol groups. Gray values for the three concentration groups $(0.1,0.2$ and $0.3 \mathrm{mg} / \mathrm{ml})$ were lower than those for the blank control group and the differences were statistically significant $(\mathrm{P}<0.05)$ (Fig. 2).

\section{Discussion}

Skin cancer is the malignant proliferation of epidermal keratinocytes, including squamous cell and basal cell carcinoma (7). In recent years, the incidence of skin cancer has been on the increase. The disease is associated with environmental pollution and other factors causing the destruction of the ozone layer, resulting in an increase in ultraviolet radiation reaching the earth, and leading to the passive acceptance of irradiation intensity (8). At present, the specific pathogenesis of skin cancer remains unclear, and clinical treatment of skin cancer is also limited. Identification of a new and effective natural medicine for the prevention and treatment of skin cancer has become one of the issues to be solved. In recent years, the in-depth study of resveratrol has revealed antagonistic activity on many types of tumor cells, such as liver (9), gastric (10), esophageal (11), breast (12), and cervical cancer (13), as well as leukemia (14), whose mechanism may be associated with the change of telomerase activity (15). However, there are currently no studies available regarding whether resveratrol affects skin cancer cell proliferation, apoptosis and telomerase activity. Therefore, in the present study, we provided a theoretical basis for the use of resveratrol as a clinical treatment for skin cancer.

Telomere is a short section of DNA-protein complex located at the end of the eukaryotic chromosome arm, whose function is to protect the chromosome (16). Telomerase is a specific chromosome terminal transferase, whose main function is taking its RNA as a template. Catalytic synthesis of the telomeric repeat sequence of the ends of chromosomes makes up for the loss of telomeric DNA cell division and causes infinite cell proliferation, and its expression level is closely associated with the occurrence, development and prognosis of malignant tumors. In the majority of tumor cells, there is an abnormal expression of telomerase activity, whereas in normal human cells telomerase activity cannot be detected. Activation of telomerase is one of the key links of malignant tumors, whose activity can be achieved through the regulation of telomerase RNA component and/or protein components, of which catalytic subunit hTERT is the most important (17).

In the present study, resveratrol intervention in A431 cells, resulted in typical morphological features of apoptosis. MTT assay results after different concentrations of resveratrol intervention showed that A431 cell proliferation was inhibited to some extent, and the inhibition increased with the increase of resveratrol concentration, indicating that this inhibition is dose-dependent. The results of the detection of telomerase 
activity experiment showed that resveratrol inhibited the telomerase activity of A431 cells and was independent of the concentration. A431 cells treated with different concentrations of resveratrol for $24 \mathrm{~h}$ showed that the expression of hTERT protein was significantly lower, as detected by western blot analysis.

The experimental results showed that resveratrol inhibit A431 proliferation of human epidermoid carcinoma cells, inducing its apoptosis, the mechanism of which may be associated with the inhibition of hTERT mRNA transcription, decreasing the protein expression, thereby reducing the activity of telomerase.

In conclusion, resveratrol is capable of downregulating the expression of hTERT protein and inhibits the ability of telomerase of A431, which is an important mechanism of action of resveratrol with regard to inhibition of A431 cell proliferation.

\section{Acknowledgements}

This study was funded by Xuzhou Science and Technology Plan Project (no. XM08C048).

\section{References}

1. Chen W and Yang H: Progression of anticancer mechanism of resveratrol. Int J Pathol Clin Med 28: 403-407, 2014.

2. Pearce VP, Sherrell J, Lou Z, Kopelovich L, Wright WE and Shay JW: Immortalization of epithelial progenitor cells mediated by resveratrol. Oncogene 27: 2365-2374, 2008.

3. Fuggetta MP, Lanzilli G, Tricarico M, et al: Effect of resveratrol on proliferation and telomerase activity of human colon cancer cells in vitro. J Exp Clin Cancer Res 25: 189-193, 2006.

4. Boukamp P, Popp S and Krunic D: Telomere-dependent chromosomal instability. J Investig Dermatol Symp Proc 10: 89-94, 2005 .
5. Cairney CJ and Keith WN: Telomerase redefined: Integrated regulation of hTR and hTERT for telomere maintenance and telomerase activity. Biochimie 90: 13-23, 2008.

6. Kyo S, Takakura M, Fujiwara T and Inoue M: Understanding and exploiting hTERT promoter regulation for diagnosis and treatment of human cancers. Cancer Sci 99: 1528-1538, 2008.

7. Ping W and Bi Z: Progress in the study of molecular mechanism of skin cancer induced by UVB. Foreign Med Sci 31: 44-46, 2005.

8. Li L and Bai X: Effects of ultraviolet radiation on human skin health. Hyg Sect Foreign Med Sci 35: 198-201, 2008.

9. Huang D, Shan H and Xie W: Molecular mechanisms of metastasis in hepatoma carcinoma cells induced by resveratrol. Acta Univ Med Anhui 48: 1071-1074, 2013.

10. Liu X, Zhao W and Qiu G: Effects of resveratrol on proliferation and expression of matrix metalloproteinase-9 in gastric carcinoma cells. J Xi'an Jiaotong Univ Med Sci 32: 606-609, 2011.

11. Zhang L, Tan Z, Chen W, Yang G, Wu Y and Xu J: Effect of resveratrol on growth and apoptosis of human esophageal cancer cells. Med J Wuhan Univ 28: 54-57, 2007.

12. Guo H, Zhang X: The inhibitory action of resveratrol on proliferation of MCF-7 breast cancer cells. Chin J Clin Oncol 38: 1424-1426, 2011

13. Zhang P, Sun Y, Yao Y and Liu J: Effects of resveratrol on female reproductive system malignant tumors. J Dalian Med Univ 37: 403-407, 2015.

14. Xiong X and Ann C: Research progress of resveratrol on antitumor. Heilongjiang Med J 23: 59-61, 2010.

15. Lanzilli G, Fuggetta MP, Tricarico M, Cottarelli A, Serafino A, Falchetti R, Ravagnan G, Turriziani M, Adamo R, Franzese O, et al: Resveratrol down-regulates the growth and telomerase activity of breast cancer cells in vitro. Int J Oncol 28: 641-648, 2006.

16. Wojtyla A, Gladych M, Rubis B: Human telomerase activity regulation. Mol Biol Rep 38: 3339-3349, 2011.

17. Fujiwara $T$ and Tanaka N: Telomerase-specific oncolytic virotherapy for human cancer with the hTERT promoter. Uirusu 58: 11-18, 2008. 